\title{
Squabble over risks of probiotic infant formula
}

$\mathrm{T}$ he labels on cans of a probiotic brand of infant formula sold by Nestlé Canada Inc. contain potentially deadly instructions, according to INFACT Canada, an advocacy organization that promotes breastfeeding.

The formula, Nestlé Good Start Natural Cultures, contains Bifidobacteria lactis, a strain of bacteria found in breast milk. Its label states that warming the formula to temperatures above $40^{\circ} \mathrm{C}$ will "compromise the natural cultures." But the World Health Organization (WHO), in its Guidelines for Safe preparation, storage and handling of powdered infant formula, recommends that infant formula be mixed with water at a minimum temperature of $70^{\circ} \mathrm{C}$ to minimizes the risk of potentially deadly infections (brain, blood and intestinal) caused by Enterobacter sakazakii, a type of bacteria that has been found in powdered infant formula.

"Combining a contaminated product with incorrect conditions for the use of the product is totally inappropriate. You really have a deadly brew," says Elisabeth Sterken, director of INFACT Canada. "To subvert health needs to marketing needs is unconscionable."

Probiotic infant formulas have been sold in Europe and Asia for more than 15 years but have been slower to catch on in North American. Nestlé launched

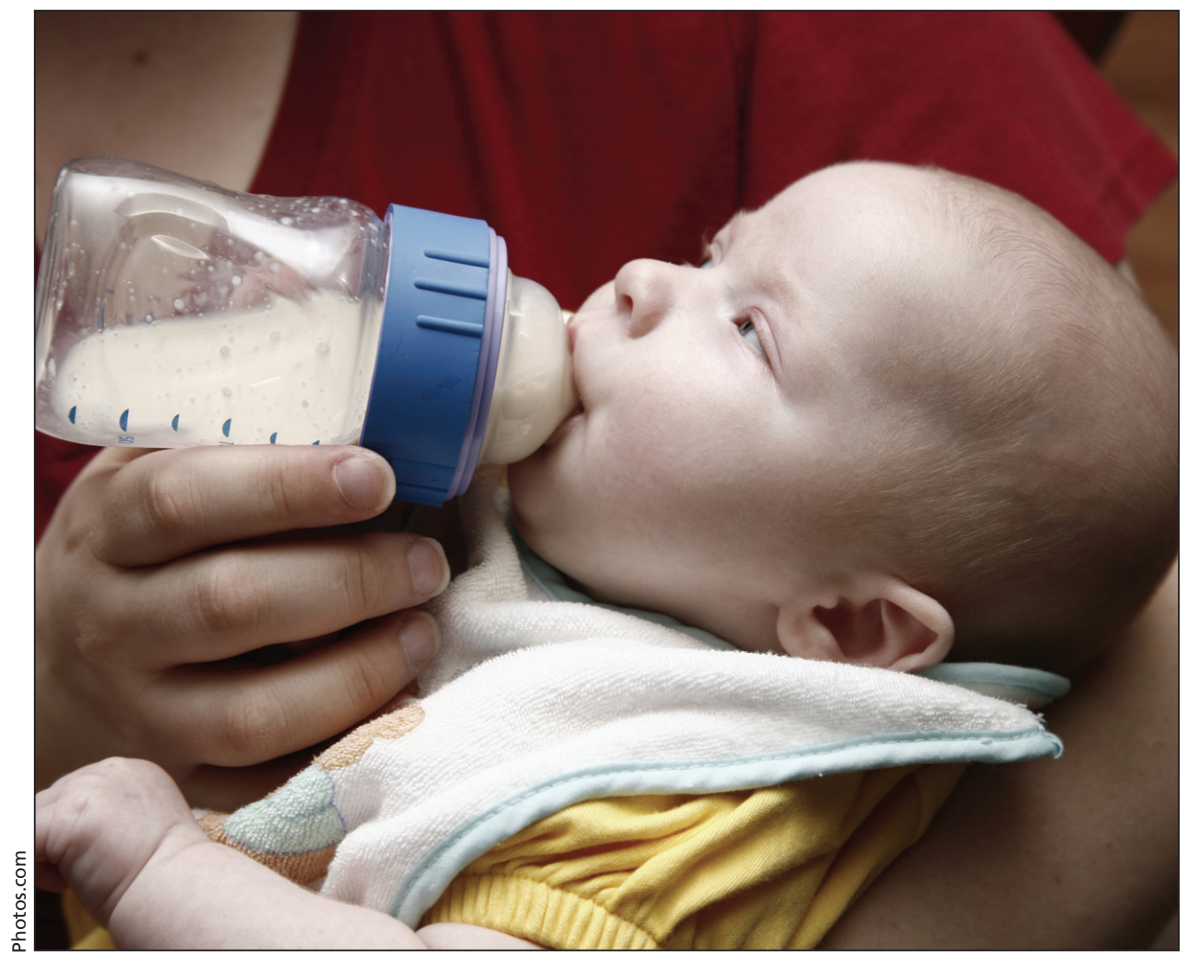

An advocacy group says the instructions on probiotic infant formula put babies at risk.

lines. Nestlé Canada Inc., however, says that its product is safe even if prepared at temperatures far lower than recommended by the WHO.

"In Canada, infant formula is regulated by Health Canada; as such, we follow Health Canada guidelines. Therefore, although the WHO Guide-

\section{"We have to make sure that what we are doing in that first year of life is beneficial down the road." - Gregor Reid, Cana- dian Research and Development Centre for Probiotics}

Good Start Natural Cultures in the United States in 2007. In April 2009, INFACT Canada released a notice to its members condemning the formula for contravening international guide- lines on Safe preparation, storage and handling of powdered infant formula specify preparation of formula with water that is $70^{\circ} \mathrm{C}$, these guidelines are not applicable in Canada," Stacey
Brown, manager of corporate affairs for Nestlé Canada Inc., wrote in an email to $C M A J$.

"As an international authority, the WHO must take many factors into account, including countries with poor water quality, as well as socioeconomic factors (education, income, etc.). In Canada, our water supply is one of the highest qualities in the world and is continually monitored for safe levels of contaminants (including bacterial pathogens). Boiling water ensures sterility and with safe preparation and handling practices, the risk of contamination is even more greatly reduced."

Health Canada likewise says that the infant formula can be safe if mixed with water at temperatures below $70^{\circ} \mathrm{C}$. In an email to CMAJ, Philippe Laroche, a Health Canada media relations officer, writes: "The World Health Organization recommendations are an excellent way to prepare pow- 
dered infant formula to reduce or eliminate the bacteria and other pathogens that could potentially be present in these products. However, there are other steps that could be taken as an alternative to these recommendations. For example, serving the formula immediately after preparation using cooled boiled water and/or potable water and keeping the reconstituted formula in the refrigerator for not more than 24 hours are also options that would ensure a safe product."

Sterken takes issue with points raised by Brown and Laroche. First, the quality of Canada's water supply is irrelevant, she says, because the contaminant is found in the formula, not the water. If previously boiled water is allowed to cool to $40^{\circ} \mathrm{C}$ before being mixed with the formula, the risks associated with
Enterobacter sakazakii will remain. With respect to the Health Canada stance that alternative preparation methods are also safe, Sterken says that might be true in theory but not in practice.

"The practicality of such rigorous requirements is not conducive to the way the product is in fact being used," says Sterken. "The 70-degree condition is important because it is the most practical way to get the best kill ratio of a dangerous contaminant."

Sterken also claims that Nestle is exaggerating the benefits to infants of the Bifidobacteria lactis in its formula, as well as making misleading comparisons with breast milk. On its website, Nestlé states: "Natural cultures are part of what gives breast milk its naturally protective qualities. And of the natural cultures found in breast-fed babies, one is by far the most prevalent - Bifidobacteria."

"It's exploitation, really," says Sterken. "They are attempting to make the product sound better than it really is. The claims are not scientifically substantiated."

Gregor Reid, director of the Canadian Research and Development Centre for Probiotics in London, Ontario, says there is no evidence that probiotics are harmful to children. Still, he says, more research is needed to determine the long-term effects of feeding infants probiotic-laced formula. "We have to make sure that what we are doing in that first year of life is beneficial down the road." Roger Collier, CMAJ

DOI:10.1503/cmaj.091103 